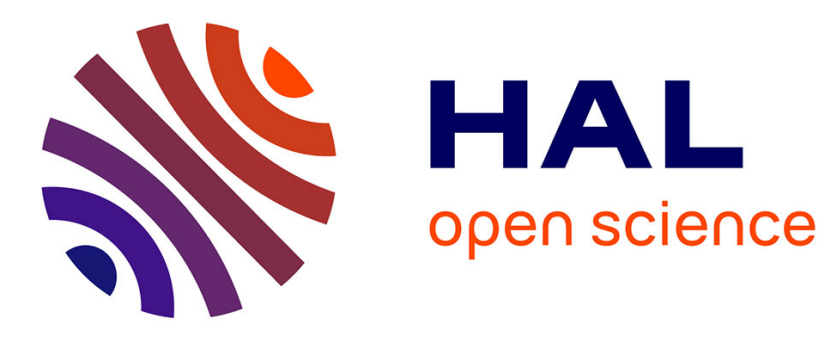

\title{
Lenalidomide in combination with dexamethasone: effective regimen in patients with relapsed or refractory multiple myeloma complicated by renal impairment
} Ulrike Klein, Kai Neben, Thomas Hielscher, Christiane Heiss, Anthony D. Ho, Hartmut Goldschmidt

\section{To cite this version:}

Ulrike Klein, Kai Neben, Thomas Hielscher, Christiane Heiss, Anthony D. Ho, et al.. Lenalidomide in combination with dexamethasone: effective regimen in patients with relapsed or refractory multiple myeloma complicated by renal impairment. Annals of Hematology, 2010, 90 (4), pp.429-439. 10.1007/s00277-010-1080-4 . hal-00583544

\section{HAL Id: hal-00583544 \\ https://hal.science/hal-00583544}

Submitted on 6 Apr 2011

HAL is a multi-disciplinary open access archive for the deposit and dissemination of scientific research documents, whether they are published or not. The documents may come from teaching and research institutions in France or abroad, or from public or private research centers.
L'archive ouverte pluridisciplinaire HAL, est destinée au dépôt et à la diffusion de documents scientifiques de niveau recherche, publiés ou non, émanant des établissements d'enseignement et de recherche français ou étrangers, des laboratoires publics ou privés. 


\title{
Lenalidomide in combination with dexamethasone: Effective regimen in patients with relapsed or refractory Multiple Myeloma complicated by renal impairment
}

\author{
Ulrike Klein ${ }^{1}$, Kai Neben ${ }^{1}$, Thomas Hielscher ${ }^{2}$, Christiane Heiß², Anthony D. Ho ${ }^{1}$, Hartmut Goldschmidt ${ }^{1,3}$
}

\author{
${ }^{1}$ University of Heidelberg, Department of Internal Medicine V, Hematology and Oncology, INF 410, D-69120 \\ Heidelberg, Germany \\ ${ }^{2}$ Department of Biostatistics, German Cancer Research Centre, INF 280, D-69120 Heidelberg, Germany \\ ${ }^{3}$ National Center for Tumor Diseases Heidelberg, INF 350, 69120 Heidelberg, Germany
}

Corresponding Author: Ulrike Klein, Department of Internal Medicine V, University of Heidelberg, INF 410, 69120 Heidelberg, Germany;

E-Mail Ulrike.Klein2@med.uni-heidelberg.de phone: +49 (0)6221 56 8611; fax: +49 (0)622156 5721

Running header: Lenalidomide in patients with Multiple Myeloma 


\begin{abstract}
Over the last decade, treatment options for patients with Multiple Myeloma (MM) have improved substantially, resulting in better response rates and prolonged overall survival. Nevertheless, MM remains a challenging disease, especially if renal insufficiency (RI) or extensive pre-treatment aggravates the assignment of the optimal treatment schedule. In this retrospective study, we analyzed the outcome of lenalidomide + dexamethasone in 167 patients with relapsed or refractory MM with focus on RI. The baseline creatinine clearance ( $\mathrm{CL}_{\mathrm{C}_{r}}$ ) was normal in 94 patients $\left(\mathrm{CL}_{\mathrm{c}_{r}} \geq 80 \mathrm{~mL} / \mathrm{min}\right.$ ), while a RI was observed in 73 patients, including 40 patients with mild $\left(50 \leq \mathrm{CL}_{\mathrm{cr}}<80 \mathrm{~mL} / \mathrm{min}\right)$ and 33 patients with moderate or severe $\mathrm{RI}\left(\mathrm{CL}_{\mathrm{Cr}_{\mathrm{r}}}<50 \mathrm{~mL} / \mathrm{min}\right)$. Response rates declined depending on the severity of RI, being $67 \%$ among patients with normal kidney function, $60 \%$ among patients with mild $\mathrm{RI}$ and $49 \%$ among patients with moderate or severe RI. Time to progression (TTP) was significantly reduced in patients with severe $\mathrm{RI}$ and in case of $>2$ previous treatment lines. Overall survival (OS) was not significantly different between patients with normal and impaired renal function. In contrast, the number of previous treatment lines ( 2 versus $<2$ ) and the use of novel agents like bortezomib or thalidomide prior to lenalidomide + dexamethasone therapy had a more adverse effect on OS. In conclusion, lenalidomide + dexamethasone is an effective regimen for relapsed or refractory patients with MM complicated by RI with manageable toxicity.
\end{abstract}

Keywords: Multiple Myeloma, Lenalidomide, renal insufficiency, pre-treatment 


\section{Introduction}

Considerable effort has been put into understanding the pathomechanism of Multiple Myeloma (MM), optimizing diagnostic procedures and therapeutic strategies, leading to substantial advances in treatment options and survival duration in the last decade, mostly due to new therapeutic agents ]. However, MM remains a challenging hematological neoplasm. Lenalidomide is an agent with proven efficacy and tolerability in relapsed and newly diagnosed patients. Its targets are not only the MM cell, but also cell-host interactions, cytokine-secretion and the BM milieu ]. Management of MM patients is often complicated by the fact that up to 20 to $40 \%$ of patients suffer from renal insufficiency (RI) ]. The main reason for this is the accumulation and precipitation of light chains forming casts, resulting in renal tubules obstruction. They also seem to alter renal function by direct toxic effects on the proximal renal tubules; hypercalcemia and dehydratation, with nephrotoxic medication enhancing this renal damage ]. Advanced age of MM patients can also be a cofactor for renal insufficiency, as it might be associated with an increased incidence of cardiovascular or endocrine disorders. Data from retrospective analyses and sub-analyses of prospective trials for conventional chemotherapy reveal that TTP and OS are reduced in patients with renal insufficiency ]. Therefore, effective treatment modalities having no or little renal toxicity and the potential ability to improve renal impairment are preferred. In the literature, bortezomib has been identified to be the best choice for these patients, particularly as no dose adjustment is needed for any degree of renal insufficiency and response and improvenment of renal function take place rapidly. In case of impaired renal function, therapy with lenalidomide requires adjustment to be feasible. Oral absorption, protein binding, or non-renal elimination of lenalidomide are not altered by RI. However, renal clearance of lenalidomide decreases drastically in patients with severe renal dysfunction, whereas drug exposure and half-life time are increased. Therefore, dose adjustments are recommended for patients with a creatinine clearance $\mathrm{CL}_{\mathrm{cr}}$ of less than $50 \mathrm{ml} / \mathrm{min}$ ]. Prospective data from clinicals trials on the application of lenalidomide in patients with MM and renal impairment, however, are not available.

As data from randomized studies are lacking, the question of when to best apply salvage therapy in relapsed or refractory disease remains to be discussed as controversially as the correct implementation of new therapeutic agents, particulary since these agents took place in various upfront strategies. It is well known that the probability of treatment response decreases with increasing numbers of previous therapies ]. In addition, the time to progression is abbreviated with each salvage therapy applied.

The current investigation is a retrospective analysis to evaluate the influence of renal impairment and previous therapies in patients with relapsed MM who have been treated with lenalidomide at a single center. 


\section{Patients and Methods}

Between July 2005 and June 2009, 167 patients with refractory or relapsed MM were treated at our center with a combination of lenalidomide and dexamethasone. Treatment consisted of lenalidomide (25 $\mathrm{mg}$ on day 1 to 21 ) and dexamethasone (cycle duration 28 days) according to the two phase III studies, wich lead to the approvel of lenalidomide in relapsed and refractory MM patients [18;19]. The first 13 pts (7.8\%) received high-dose dexamethasone with $40 \mathrm{mg}$ day $1-4,9-12,17-20$ but due to severe infectious complications we decided in our center to reduce the dosage for all patients about $50 \%$ to $20 \mathrm{mg}$ day 1 4, 9-12 and 17-20. One-hundred-thirty-two patients (79.0\%) received this schema. With the emerging data of the low-dose dexamethasone schedule of Rajkumar et al. 12 patients (7.2\%) received the reduced dosage of dexamethasone according to the ECOG E4A03 study with $40 \mathrm{mg}$ on days 1, 8, 15 and 22 because of expected severe side effects of dexamethasone due to their personal risk profile. Of the 20 patients who received lenalidomide/dexamethsone after allogenic transplantation and due to the concomitant immunosuppressive therapy, 8 patients $(4.8 \%)$ got a further reduced dexamethasone dosage ( 2 pts. $0 \mathrm{mg}$ dexamethasone, 4 pts. $80 \mathrm{mg}$ per cycle, 1 pt $96 \mathrm{mg}$ per cycle and 1 pt $144 \mathrm{mg}$ per cycle). The remaining 2 patients received $80 \mathrm{mg}$ and $120 \mathrm{mg}$ per cycle respectively as an individualized treatment decision.

Dose adjustments for patients with RI were made in case of a baseline $\mathrm{CL}_{\text {cr }} \leq 50 \mathrm{~mL} / \mathrm{min}$ or worse. Patients with a moderate $\mathrm{RI}\left(30 \leq \mathrm{CL}_{\mathrm{cr}_{r}} \leq 50 \mathrm{~mL} / \mathrm{min}\right)$ received $10 \mathrm{mg}$ Lenalidomide daily; patients with a severe $\mathrm{RI}\left(\mathrm{CL}_{\mathrm{Cr}}<30 \mathrm{~mL} / \mathrm{min}\right)$ received $15 \mathrm{mg}$ every other day, whereby patients requiring dialysis received lenalidomide $15 \mathrm{mg}$ after dialysis. However, $11 \mathrm{pts}$ with moderate RI received due to their borderline $\mathrm{CL}_{\mathrm{cr}}$ and the fact that their serum creatinin was below $1.7 \mathrm{mg} / \mathrm{dl}$ the full dosage with $25 \mathrm{mg}$ lenalidomide day $1-21$. One pt with a baseline $\mathrm{CrCl}$ of $25 \mathrm{ml} / \mathrm{min}$ received $25 \mathrm{mg}$ as well, because serum creatinine was normal and collectin volume of urine was only $1.200 \mathrm{ml} / 24 \mathrm{~h}$. Treatment was administered until disease progression or unacceptable toxicity occured. Lenalidomide and dexamethasone were administerd as re-induction therapy in 41 patients, followed by high dose chemotherapy and autologous stem cell transplantation (ABSCT). At the time of this analysis, 40 patients have undergone ABSCT. In the statistical analysis ABSCT was computed as a competing risk. For the analysis of RI, patients were classified into the following $\mathrm{Rl}$ subgroups based on their baseline cratinine clearance $\left(\mathrm{CL}_{\mathrm{cr}}\right)$ as determined in a 24-hour urine sample: no RI $\mathrm{CL}_{c r}>80 \mathrm{~mL} / \mathrm{min}$, mild $\mathrm{RI} 50 \leq \mathrm{CL}_{\mathrm{cr}} \leq 80 \mathrm{~mL} / \mathrm{min}$, moderate $\mathrm{RI} 30 \leq \mathrm{CL}_{\mathrm{cr}} \leq 50 \mathrm{~mL} / \mathrm{min}$ or severe $\mathrm{RI} \mathrm{CL}_{\mathrm{cr}}<30 \mathrm{~mL} / \mathrm{min}$. As the dosage of lenalidomid is linked to the classification of the GFR $(80-50 \mathrm{ml} / \mathrm{min}, 50-30 \mathrm{ml} / \mathrm{min},<30 \mathrm{ml} / \mathrm{min}$ without dialysis and dialysis dependency) we decided to classify the patients as well in these categories, even if nephrologists consider normal renal function as GFR $>90 \mathrm{ml} / \mathrm{min}$. Information on $\mathrm{CL}_{\mathrm{cr}}$ at the time of treatment initiation was available for 165 patients (98.8\%). For two patients, $\mathrm{CL}_{\mathrm{cr}}$ at start therapy was not available; therefore the MDRD-formula (MDRD = Modification of Diet in Renal Disease) was used instead. Both patients had in previous measurements always normal $\mathrm{CL}_{\mathrm{cr}}$ and at the time of beginning normal values for creatinine and urea, so they were counted as normal kidney function. Due to the relatively small number of patients with moderate to severe RI, these groups were combined for the statistical analysis. The numbers of pre-treatment were recorded for all patients. Every treatment schedule which was necessitative due to relapse or refractory disease was counted as one therapy. Induction, mobilization, autologous transplantation and maintenance therapy were counted as one 
therapy. Response to treatment was assessed according to the European Group for Blood and Marrow Transplantation criteria for complete remission (CR), partial response (PR), minimal response (MR), stable disease (SD) and progressive disease 21]. The criteria were complemented by the criteria of the International Myeloma Working Group for very good partial response (VGPR) and near complete remission (nCR) 2]. CR was defined as: no M-protein detectable by electrophoresis and immunofixation in the serum and urine, disappearance of any soft tissue plasmacytomas, and $\leq 5 \%$ plasma cells in the bone marrow. nCR was defined as complete disappearance of the monoclonal protein, except for a positive immunofixation. VGPR was defined as at least $90 \%$ reduction in serum M-protein and urine Mprotein level below $100 \mathrm{mg} / 24$ hours. PR was defined as at least $50 \%$ reduction of serum M-protein and reduction in 24 -hour urinary sample M-protein by at least $90 \%$ or less than $200 \mathrm{mg} / 24$ hours. MR was defined as a 25 to $49 \%$ reduction in serum M-protein and reduction in 24-hour urinary sample M-protein by 50 to $89 \%$. Progressive disease was defined by any of the following: an increase of at least $25 \%$ from baseline serum or urinary M-protein, equalling at least an absolute increase of at least $500 \mathrm{mg} / \mathrm{dL}$ in serum or $200 \mathrm{mg} / 24$ hours in urine; newly occured or increased size of bone lesions or soft-tissue plasmacytomas, or development of hypercalcemia. Efficacy was measured by overall response rate (ORR), which is defined as CR+VGPR+PR rate. ORR was assessed as best response during treatment with lenalidomide and dexamethasone. Time to progression (TTP) was evaluated as time from start of lenalidomide/dexamethasone to first assessment of disease progression. Patients without evidence of progression were censored at their last information. Overall survival (OS) was defined as start of lenalidomide/dexamethasone until death from any cause or last follow-up visit, whichever occurred first. Follow-up data on OS were obtained up to June 2009, for a median follow-up duration of 15.7 months. The review board of our institution approved of the retrospective analysis and patients provided written informed consent. 


\section{Statistical analysis}

Estimation of OS distribution was performed by the method of Kaplan and Meier. For comparisons of OS curves, the log-rank test was used. In addition, Cox PH regression analysis was used to evaluate the prognostic impact in a univariate model as well as in a multivariate model together with prognostically relevant clinical factors. TTP was evaluated in a competing risk analysis with ABSCT being the competing risk. TTP was analysed fitting a subdistributional hazard regression model [32]. This model directly assesses the effect of a prognostic factor on TTP in a competing risk setting and allows incorporating additional covariates. TTP distribution was estimated using cummulative incidence rates. Post-baseline factors were included as time-dependent covariates. Response rates were compared with Fisher's exact test. The result of a test was always judged as statistically significant when the corresponding two-sided $p$-value was below 0.05 . The prognostic value of clinical factors was assessed by their estimated hazard ratios including $95 \%$ confidence intervals. All statistical computations were performed with the statistical software environment $\mathrm{R}$, version 2.9.0 using the $\mathrm{R}$ package cmprsk version 2.2-0 using the $\mathrm{R}$ add-on packages cmprsk and kmi [33].

A propensity score analysis was performed to account for imbalances at baseline between patients with severe and without renal impairment, adjusting for age, sex, number of previous therapies, previous treatment with velcade, thalidomide or both, time between start of first-line treatment and start of lenalidomide, and time between last multiple myeloma treatment and start of lenalidomide. Adjusted Kaplan-Meier curves for OS were computed using the propensity scores in an inverse probability weighting scheme 3]. 


\section{Results}

\section{Patients}

From July 2005 to June 2009, 167 patients with relapsed or refractory MM were treated with lenalidomide/dexamethasone in our center, forming the base of this analysis. Normal renal function with no $\mathrm{RI}\left(\mathrm{CL}_{\mathrm{Cr}_{r}} \geq 80 \mathrm{~mL} / \mathrm{min}\right.$ ) was observed in 94 patients, $40(23.9 \%)$ patients had mild $\mathrm{RI}\left(50 \leq \mathrm{CL}_{\mathrm{cr}_{\mathrm{r}}}<80\right.$ $\mathrm{mL} / \mathrm{min}), 21(12.6 \%)$ had moderate $\left(30 \leq \mathrm{CL}_{\mathrm{cr}}<50 \mathrm{~mL} / \mathrm{min}\right)$ and 12 patients $(7.2 \%)$ had severe $\mathrm{RI}\left(\mathrm{CL}_{\mathrm{Cr}}\right.$ $<30 \mathrm{~mL} / \mathrm{min}$ ), of whom 5 patients $(3 \%)$ required hemodialysis. Further baseline characteristics are presented in table 1 . When compared to patients without $\mathrm{RI}$, patients with $\mathrm{RI}$ were more likely to be female and patients with normal renal function were more likely to have a lower median number of previous therapies ( 2 versus 3 in mild $\mathrm{RI}$ and 3 in severe $\mathrm{RI}$ ) and are less likely to have received bortezomib and/or thalidomide prior to lenalidomide/dexamethasone when compared to patients with mild or severe RI (22.3\% vs. $45.0 \%$ vs. $36.4 \%)$.

\section{Efficacy}

Among the entire group, the overall response rate $(\geq P R)$ was $61.7 \%$, while the $C R$ rate was $11.4 \%$. Overall response rates and $\mathrm{CR}$ rates declined depending on the severity of renal impairement, being $67.0 \%$ among patients with normal kidney function (CR 14.9\%), 60.0\% among patients with mild RI (CR $10.0 \%$ ) and $48.5 \%$ among patients with moderate or severe RI (CR 3.0\%) (ORR adj. p-value 0.66). Efficacy was also strongly influenced by the type of pre-treatment and the occurence of relapse from remission or primary refractory disease. A detailed description is listed in table $2 a$.

\section{Time to progression (TTP)}

TTP was defined as time from start of RD therapy until disease progression. During the follow-up of 15.7 month, a total of 101 events occurred. The median TTP based on the cumulative incidence function for the overall population is 9.02 months. TTP is significantly shortened in case of mild $(p=$ 0.007 ) and $\geq$ moderate RI ( $p=0.005$ ) versus no renal impairment (Fig. 2a). In order to identify the effect of more intense pre-treatment in patients with renal impairment, we performed a multivariate analysis. The following parameters were considered in addition to kidney function and previous treatment schedules within a multivariate Cox $\mathrm{PH}$ model: age, previous therapies $(1,2,>2)$, previous new agents (bortezomib, thalidomide, both), time between first myelomaspecific therapy and RD therapy, time between last treatment and RD therapy, progressive disease during treatment with new agents, prior allogeneic transplantation and quality of response ( $\geq \mathrm{PR})$. Multivariate analysis revealed that the quality of response $(p=0.03)$, severe renal impairment $(p=0.04)$, more than two previous treatment lines $(p=$ 0.03 ) and time between last treatment and RD therapy $(p=0.02)$ were significantly related to TTP. The median TTP lies between 13.02 months among patients with no RI, 7.67 months among patients with mild RI and 6.00 months among patients with severe kidney dysfunction. The TTP according to the kind of pre-treatment revealed the following results: median TTP not reached for patient with no history of novel agents, 11.34 months for patients who only received previous thalidomide, 8.92 months among patients who were prior exposed to bortezomib only and 5.57 months among patients who received 
both new agents before the treatment with lenalidomide/dexamethasone (Fig. 2c). Based on the hazard ratio we calculated a forest plot to illustrate the impact of the different parameters on TTP (Fig. 1a).

\section{Overall survival}

Overall survival was defined as time from start of lenalidomide/dexamethasone therapy until death from any cause. After a median follow-up of 15.7 months, death occurred in 62 patients ( 29 among patients with normal kidney function, 17 among patients with mild RI and 16 among patients with moderate/severe RI), with a median time to death of 25.8 months. With regards to RI, no significance could be detected in the differentiation between normal kidney function and all severity codes of renal impairment $(p=0.233)$ (Fig. $2 b)$. There was a trend towards shorter duration of survival $(p=0.107)$ among patients with severe $\mathrm{RI}\left(\mathrm{CL}_{\mathrm{Cr}}<50 \mathrm{~mL} / \mathrm{min}\right)$ when compared to patients with normal kidney function. This trend, however, was not significiant. Patients who had received bortezomib or thalidomide prior to lenalidomide/dexamethasone had a significant shorter duration of survival when compared to patients treated with schedules without new agents $(p=0.018)$, with bortezomib $(p=0.011)$ having a stronger influence than thalidomide $(p=0.103)$. In case both new agents were applied prior to lenalidomide/dexamethasone, overall survival was negatively impacted $(p<0.001)$ (Fig. $2 d)$. Similar results were seen when regarding the number of previous treatment lines: patients with $2(p=0.028)$ or more than 2 pre-treatment schemes $(p<0.001)$ had a significant shorter duration of overall survival. A detailed description is shown in table 2b. Results are illustrated as forest plot as well (Fig. 1b). In order to verify the influence of other variables we performed a multivariate analysis. The following parameters were considered within a multivariate Cox $\mathrm{PH}$ model: age, previous therapies $(1,2,>2)$, previous new agents (bortezomib, thalidomide, both), time between first myelomaspecific therapy and RD therapy, time between last treatment and RD therapy, progressive disease during treatment with new agents, stem cell transplantation after RD therapy (time dependent co-variate), prior allogeneic transplantation and quality of response $(\geq \mathrm{PR})$. In multivariate analysis the time between first myelomaspecific therapy and RD therapy $(p=0.03)$ and the quality of response $(p=0.02)$ were significant. Additionally a propensity score analysis was performed to account for imbalances at baseline. The following baseline covariates are used to model the probability of having a severe renal impairment compared to having no renal impairment: age, sex, number of previous therapies, previous treatment with velcade, thalidomide or both, time between first MM treatment and start of RD, and time between last MM treatment and start of RD therapy (Fig. 3).

\section{Toxicity}

Due to the retrospective nature of the study, complete toxicity data are not available for all patients. We therefore performed a subgroup analysis of 108 patients with available toxicity information referring to haematological toxicity, infectious complication and thromboembolic events. Patients with renal insufficiency had a higher incidence of neutropenia than patients with normal kidney function $(p=0.05)$. RI was also associated with a higher incidence of infections $(p=0.03)$ especially with pneumonia $(p=$ 0.03). Thrombocytopenia was not significantly different. Anemia naturally occurred more frequently in 
the group of patients with renal impairment due to additional renal caused anemia. Thromboembolic events did not differ in the subgroups.

The tolerance of therapy with lenalidomide/dexamethasone was additionally measured by the frequency of dose reduction or discontinuation of therapy. These data are available for all patients. In 58 of 167 patients $(34.7 \%)$ either therapy interruption or dose reduction was necessary. While patients with severe $\mathrm{RI}$ more often required interruption of treatment, for patients with moderate RI more frequently a dose reduction was performed ( 24.2 vs. $12.5 \%$ and 24.2 vs. $30.0 \%$ ). In the Fisher exact test the reduction of therapy reveals significance $(p=0.02)$ in case of $\mathrm{Rl}$, whereby in the testing for discontinuation of treatment, data do not reach significance $(p=0.67)$. Further information on toxicity can be found in tables $3 a$ and $3 b$.

\section{Alterations of renal impairment during lenalidomide/dexamethasone treatment}

Among 167 patients, 152 were evaluable for follow-up $\mathrm{CL}_{\mathrm{cr}}$, of which 64 patients suffered from $\mathrm{RI}$ at baseline. Principally it needs to be taken into consideration that the pathogenesis of renal impairment remains unclear in the main proportion of patients. Beside myeloma specific alterations, RI is probably related to other than myeloma associated factors as well.

No alteration in the degree of renal impairment was seen in 123 of 152 patients $(80.9 \%)$. When regarding patients with renal insufficiency at the beginning of therapy 17 of 64 (26.6\%) showed an improvement of at least one level of the previously described subclasses. On the contrary, $\mathrm{CL}_{\mathrm{cr}}$ had deteriorated in 8 of 64 patients (12.5\%). However, 2 of these 8 patients had suffered from progressive disease at the time of deterioration of their renal function. We subsequently looked at the relationship between the improvement of renal function and the response to RD treatment. Patients who experienced an improvement or a stabilization of their kidney function noticeably obtained a higher frequency of at least a partial response than patients who experienced a worsening of their renal function. Further information is displayed in table 4. 


\section{Discussion}

Our data demonstrate that lenalidomide is highly active in relapsed and refractory MM patients. Even with impaired renal function or previous treatment schedules with new agents a remarkable overall response rate of about $62 \%$ and a CR rate of $11.4 \%$ can be reached. Nevertheless, response rates decreased with the extent of renal impairment from $67 \%$ to $48.5 \%$. It needs to be taken into account that this is not mainly an effect of the severity of renal impairment but the impact of more prior therapies in the two groups with $\mathrm{RI}$ and a higher percentage of bortezomib containing regimes. This imbalance applies as well for the TTP which is significantly shortened in univariate analysis in case of mild and $\geq$ moderate RI. To account for these heterogenities we performed a multivariate analysis regarding TTP and OS. Multivariate analysis was only significant in patients with severe kidney dysfunction according the TTP. This finding is mainly caused by the significantly higher frequency of dose reduction in patients with renal insufficiency due to more toxic side effects. Patients with RI had a higher incidence of neutropenia and infections. Especially the occurrence of pneumonia was more frequent than in patients with normal kidney function. Due to these adverse events treatment schedules could not be realized as planned. Delay of treatment, dose reduction and interruption entailed not only the deterioration of response rates but also explain the shortened TTP. Rajkumar et al could demonstrate that the dosereduction of dexamethasone in the combination therapy with len/dex may result in a significantly worse ORR, but due of the reduction of toxic side effects and the nessessity of less dose adjustments or dose interruptions a prolonged OS was obtained [20]. Recently, a dose adjustment protocol for patients with renal impairment was approved for use in the US and Europe. It suggests that lenalidomide $5 \mathrm{mg}$ daily be used in patients requiring dialysis. This dosage has been chosen in order to decrease the fluctuation of lenalidomide plasma-levels and the individual body-load of each single dosage. This adjustment will most likely reduce toxic side effects and improve the compliance. Due to our single-centre experience we reduced the dosage of dexamethasone per cycle about $50 \%$, from $480 \mathrm{mg}$ to $240 \mathrm{mg}$. A further reduction in analogy to the ECOG study to $160 \mathrm{mg}$ might additionally reduce toxic side effects.

A main goal in the treatment of MM patients with renal insufficiency is the improvement of kidney function. Our data demonstrated that among the 152 evaluable patients 140 pts. (92.1\%) had an unchanged renal status or an improvment of their renal impairment. Focussing on 64 patients with a $\mathrm{CL}_{\mathrm{Cr}}$ of $50 \mathrm{ml} / \mathrm{min}$ or less at baseline, $17(26.6 \%)$ had an improvement in renal function. Patients who experienced an improvement or a stabilization of their kidney function noticeably obtained a higher frequency of at least a PR than patients who experienced a worsening of their renal function. The effect of disease control through the lenalidomide/dexamethasone treatment seems to have a major impact on the course of renal function. Yet it has to bear in mind that for the main proportion of patients in our study population the pathogenesis of renal impairment remains unclear. Focussing on patients with proven solely myeloma associated renal dysfunction, would more likely result in an even higher percentage of renal function improvement.

As repeatedly mentioned lies great relevance regarding the efficacy of lenalidomide in the type, duration and sequence of previous myelomaspecific treatments. The effect of decreasing OS and TTP with each additional treatment line is a general feature for all kinds of myeloma-specific chemotherapy, reflecting the biology of the disease mainly by an increasing resistence-feature of the plasma cell. Recently published data from a subset analysis of two phase III studies with lenalidomide and dexamethasone 
suggested the greatest benefit in terms of TTP in early use ]. In our analysis, ORR diminished with increasing numbers of previous new agents from $64.3 \%$ to $52.9 \%$. In relation to intensity and type of pre-treatment, $O S$ in a univariate setting was significantly shortend after two and more previous treatments. The application of one of the two novel agents (thalidomide or bortezomib) resulted in a significant reduction of OS. While the use of thalidomide had no significant impact, previous therapy with bortezomib was significant. Applying both novel agents significantly decreased OS $(p<0.001)$. In accordance to OS, the type of previous treatment schemes affected TTP. While the influence of thalidomide showed only a trend towards a shorter duration of TTP ( $p=0.067)$, the impact of bortezomib was highly significant $(p=0.002)$. The application of both agents prior to lenalidomide was associated with a significant reduction of TTP $(p<0.001)$. With regards to mechanism of action, it can not to be anticipated that the influence of the closely related drug thalidomide is less favorable in relation to response rate and TTP than previous therapy with bortezomib 31]. In our analysis, the use of thalidomide seemed to be partly negligible, with OS and TTP being significantly influenced by the previous application of bortezomib.

The comparison of TTP and OS among different studies is limited because of varying inclusion and exclusion criteria. However, bortezomib seems to achieve a TTP duration of about 5 to 7 months in relapsed MM patients 7]. Data on the efficacy and safety of bortezomib in patients with RI from the subanalysis of the APEX study revealed that TTP was less than 4.9 months for patients with $\mathrm{CL}_{\mathrm{cr}}$ $<50 \mathrm{ml} / \mathrm{min}$ and 6.2 months for patients with moderate RI 4]. Comparable patient characteristics with 1-3 previous therapies can be found in an other phase III study which investigated the use of pegylated liposomal doxorubicin plus bortezomib versus bortezomib alone with 199 days for the bortezomib mono group and 190 days among patients with normal kidney function 8]. In the phase II CREST study, two doses of bortezomib alone or in combination with dexamethasone were evaluated as second-line therapy in MM. With the addition of dexamethasone the $1.3 \mathrm{mg} / \mathrm{m}^{2}$ cohort achieved a TTP of 11 month [29]. Patient characteristics that correlate better to our heavily pretreated cohort can be found in the phase II study in which 202 patients were enrolled. These mainly refractory patients reached an ORR $(\geq P R)$ of $27 \%$ and a median TTP of 7 month [30]. Compared to the above mentioned studies the duration of response is noticeably longer for patients receiving len/dex than bortezomib monotherapy. The TTP in our group among patients with severe RI (6.0 months) is nearly as long as for patients without renal disorder who are treated with bortezomib in the APEX study (6.3 months) or in the phase III study which investigated the use of pegylated liposomal doxorubicin plus bortezomib 8].

Considering that our investigated cohort was heavily pre-treated a median OS of 25.8 month is considerable. Although our data indicate a trend towards a shorter OS in patients with severe renal impairment compared to those with normal renal function, findings were not significant. Additionally a propensity score analysis was performed to account for imbalances at baseline, mainly the differences in the kind and intensity of previous therapies (Fig. 3). The approach of the curves is obvious and reflects the indeed sequence of events. We can demonstrate that OS is not significantly shortened in patients with severe renal insufficiency.

In conclusion, our data endorse the potency of this immunomodulatory drug even in heavily pre-treated MM patients with various degrees of renal impairment. This analysis substantiates previous data that the effectiveness is higher in its early use. However, the most favourable sequence of various new 
agents can not be deducted from our data. At this point we want to elude the limitations of our study due to its retrospective nature. Nevertheless reflects this study population the daily routine of hematologists in a university hospital. Instead, prospective trials are needed to answer the question on how to effectively sequence myelomaspecific therapy regimens. Considering the ongoing discussion of effective initial therapy with a combination of different kinds of new agents, the strategy of salvage therapy should be reconsidered as well. Lenalidomide is able to induce the longest TTP in relapsed and refractory MM patients compared to other standardized conventional myeloma therapies and achieves even in heavily pre-treated patients an improvement of renal function in a significant number of patients (25-30\%). Side effects needs to be recognized but are manageable for versed hematologists and oncologists. The new medication schedule for patients with moderate and severe renal impairment will in all likelihood reduce the problems of adverse effects, dose reduction and treatment interruption. There is no reason to generally avoid or shift the potent treatment option with lenalidomide for patients with renal insufficiency at a later time. 


\section{Acknowledgement}

The authors would like to thank Frank Müller for carefully collecting data and Fabienne McClanahan for spell checking.

This work was supportet in part by the Dietmar-Hopp-Stiftung GmbH, Walldorf, Germany

32. Fine JP, Gray RJ (1999) A proportional hazards model for the subdistribution of a competing risk. J Am Stat Assoc 94:496-509

33. R Development Core Team (2009). R: A language and environment for statistical computing. R Foundation for Statistical Computing, Vienna, Austria. ISBN 3-900051-07-0, URL http://www.Rproject.org. 


\section{Figure legends}

Fig. 1 Forestplot of univariate prognostic effects displaying the hazard ratio including 95\% confidence levels for Time to Progression (a) and Overall Survival (b)

Fig. 2 Cumulative incidence functions for Time to Progression (a, c) and Kaplan-Meier estimates for Overall Survival $(b, d)$ according to renal impairment and pre-treatment

Fig. 3 Kaplan-Meier estimates for Overall Survival by renal impairment adjusted for additional covariates according to propensity score analysis

\section{Table legends}

Tab. 1 Patient characteristics and disease features

Tab. 2a Overall response rate and time to progression duration

Tab 2b Prognostic value of various parameters on Overall Survival

Tab. 3a CTC grade 3/4 toxicity according to renal function

Tab. 3b Frequency of dose reduction and interruption according to renal function

Tab. 4 Shift in renal function during treatment with lenalidomide/dexamethasone 
a

renal insuffiency: yes vs. no

renal insuffiency: moderate vs. no

renal insuffiency: severe vs. no

renal insuffiency: severe vs. moderate/no

Thalidomide vs. no

Velcade vs. no

Velcade and Thalidomide vs. no

previous therapies: 2 vs. 1

previous therapies: $>2$ vs. 1

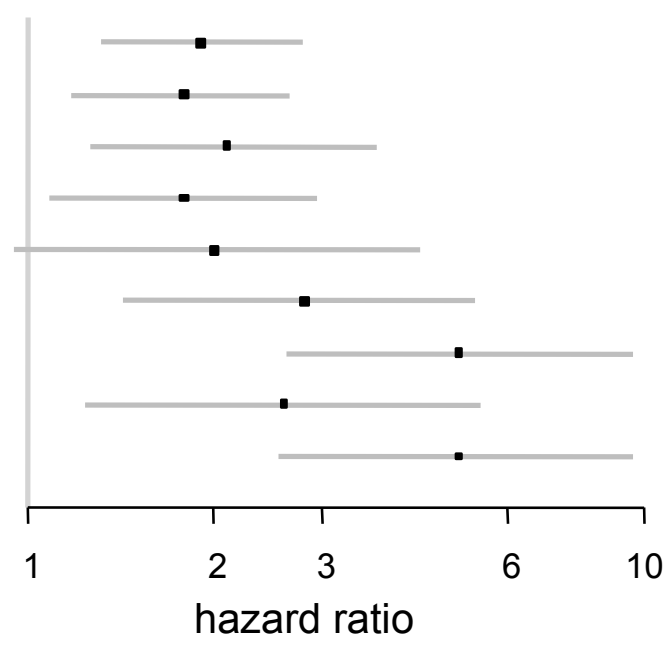

Fig. 1a Forestplot Time to progression

b renal insuffiency: yes vs. no

renal insuffiency: moderate vs. no

renal insuffiency: severe vs. no

renal insuffiency: severe vs. moderate/no

Thalidomide vs. no

Velcade vs. no

Velcade and Thalidomide vs. no previous therapies: 2 vs. 1

previous therapies: $>2$ vs. 1

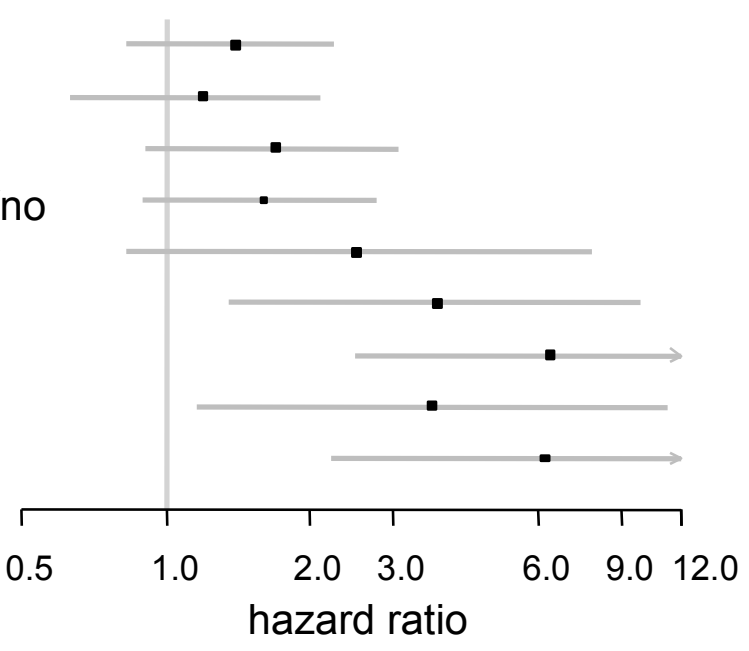

Fig. 1b Forestplot Overall survival

Fig. 1, a-b 
a Time to progression according renal impairment

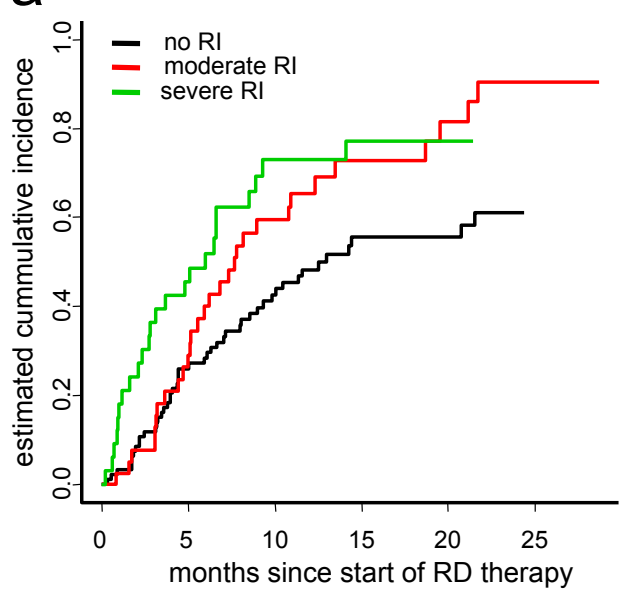

C Time to progression according pre-treatment

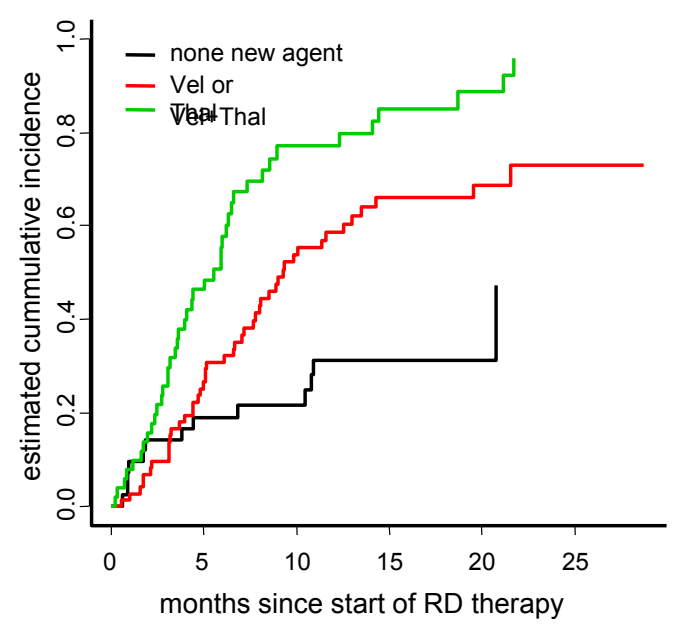

b Overall survival according renal impairment

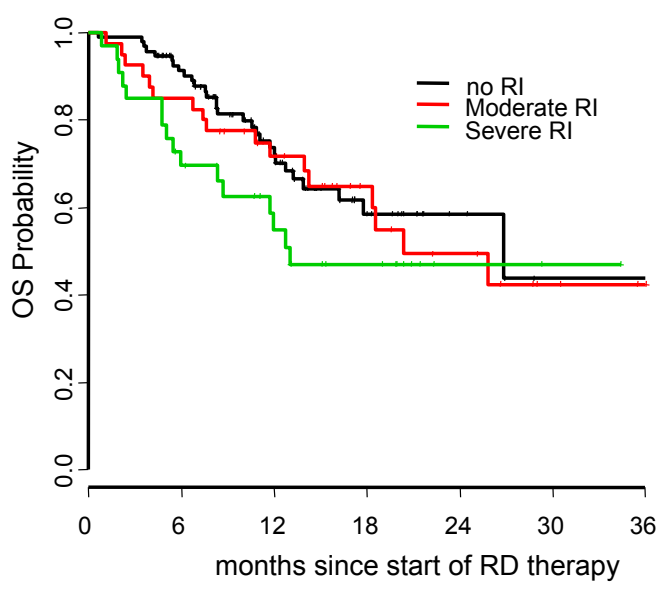

d Overall survival according pre-treatment

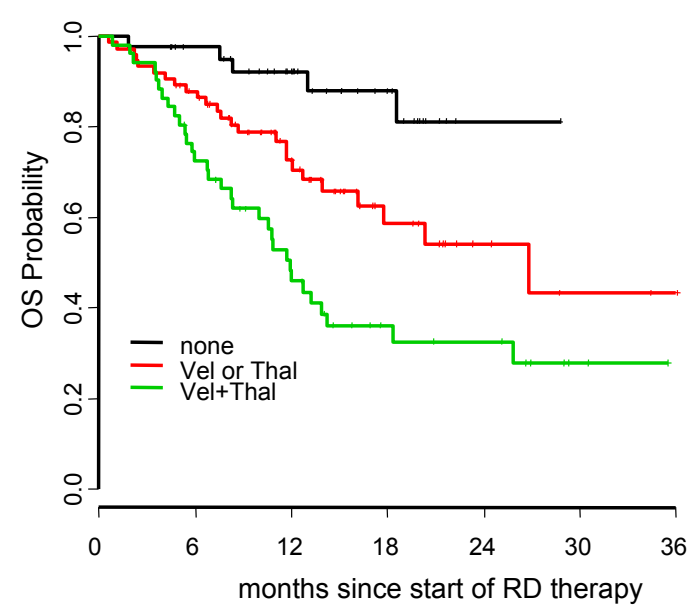

Fig. 2, a-d 
Adjusted Kaplan-Meier plot for overall survival

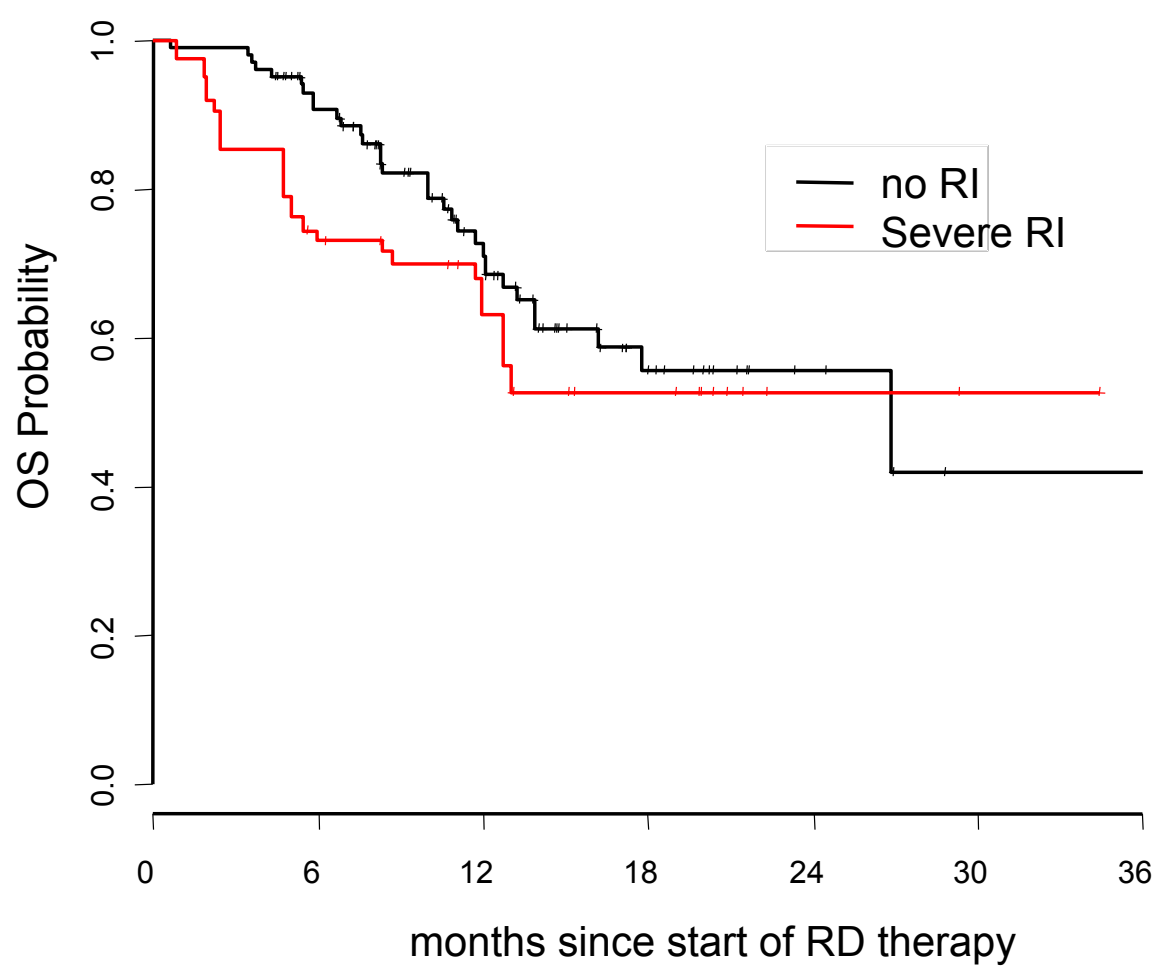

Fig. 3 
Tab. 1 Patient characteristics and disease features

\begin{tabular}{|c|c|c|c|c|c|c|}
\hline & $\begin{array}{l}\text { Normal renal } \\
\text { function }\end{array}$ & $\%$ & $\begin{array}{c}\text { Mild RI } \\
50 \leq \mathrm{CLCr}<80 \mathrm{~mL} / \mathrm{min}\end{array}$ & $\%$ & $\begin{array}{l}\geq \text { moderate RI } \\
\mathrm{CLCr}<50 \mathrm{~mL} / \mathrm{min}\end{array}$ & $\%$ \\
\hline Number of pts. & 94 & & 40 & & 33 & \\
\hline Sex (male) & $67 / 94$ & 71.3 & $14 / 40$ & 35.0 & $12 / 33$ & 36.4 \\
\hline Age median [range] & $62[30-78]$ & & $66[43-77]$ & & $66[29-80]$ & \\
\hline $\begin{array}{l}\text { Monoclonal Protein } \\
\lg \\
\lg A \\
\text { BJ } \\
\text { Other }\end{array}$ & $\begin{array}{c}60 \\
17 \\
8 \\
9\end{array}$ & $\begin{array}{l}63.8 \\
18.1 \\
8.5 \\
9.6\end{array}$ & $\begin{array}{l}23 \\
10 \\
5 \\
2\end{array}$ & $\begin{array}{c}57.5 \\
25.0 \\
12.5 \\
5.0\end{array}$ & $\begin{array}{l}15 \\
8 \\
9 \\
1\end{array}$ & $\begin{array}{l}45.5 \\
24.2 \\
27.3 \\
3.0\end{array}$ \\
\hline $\begin{array}{l}\text { Time between first diagnosis and } \\
\text { initiation of len/dex treatment in } \\
\text { month }\end{array}$ & 54.2 & & 88.7 & & 38.0 & \\
\hline $\begin{array}{l}\text { Time between first line therapy } \\
\text { and initiation of len/dex treatment } \\
\text { in month }\end{array}$ & 49.2 & & 79.4 & & 37.0 & \\
\hline $\begin{array}{l}\text { Dosage of dexamethasone/cycle } \\
\text { 480mg } \\
240 \mathrm{mg} \\
160 \mathrm{mg} \\
<160 \mathrm{mg}\end{array}$ & $\begin{array}{c}8 \\
76 \\
5 \\
5\end{array}$ & & $\begin{array}{c}5 \\
31 \\
3 \\
1\end{array}$ & & $\begin{array}{c}0 \\
25 \\
4 \\
4\end{array}$ & \\
\hline No. pre-treatment median [range] & $2[1-10]$ & & $3[1-8]$ & & $3[1-9]$ & \\
\hline Bortezomib & $46 / 94$ & 48.9 & $30 / 40$ & 75.0 & $23 / 33$ & 69.7 \\
\hline Thalidomide & $39 / 94$ & 41.5 & $22 / 40$ & 55.0 & $17 / 33$ & 51.5 \\
\hline Bortezomib and Thalidomide & $21 / 94$ & 22.3 & $18 / 40$ & 45.0 & $12 / 33$ & 36.4 \\
\hline Autologous Transplantation & $79 / 94$ & 84.0 & $36 / 40$ & 90.0 & $25 / 33$ & 75.8 \\
\hline No. cycles median [range] & $3[1-25]$ & & $5[1-30]$ & & $3[1-21]$ & \\
\hline
\end{tabular}

Abbreviations: RI, renal insufficiency; CLCr, Creatinine Clearance; pts, patients; No, number 
Tab. 2a Overall response rate and time to progression duration

\begin{tabular}{|c|c|c|c|c|c|}
\hline & & CR (\%) & $\geq$ VGPR & $\begin{array}{l}\text { ORR (\%) } \\
\text { ( } \geq P R)\end{array}$ & $\begin{array}{l}\text { Median TTP } \\
\text { (month) }\end{array}$ \\
\hline Entire group & $\mathrm{n}=167$ & $19(11.4)$ & $43(25.7)$ & $103(61.7)$ & 9.02 \\
\hline Normal kidney function & $\mathrm{n}=94$ & $14(14.9)$ & $26(27.7)$ & $63(67.0)$ & 13.02 \\
\hline Mild RI & $n=40$ & $4 \quad(10.0)$ & $12(30.0)$ & $24(60.0)$ & 7.67 \\
\hline Moderate + severe RI & $n=33$ & $(3.0)$ & $4 \quad(12.1)$ & $16(48.5)$ & 6.00 \\
\hline $\begin{array}{l}\text { No bortezomib or thalidomide as previous } \\
\text { therapy }\end{array}$ & $n=42$ & $8 \quad(19.0)$ & $16(38.1)$ & $27(64.3)$ & NA \\
\hline bortezomib or thalidomide as previous therapy & $\mathrm{n}=74$ & $(10.8)$ & $18(24.3)$ & $49(66.2)$ & 9.28 \\
\hline only thalidomide & $\mathrm{n}=27$ & $(7.4)$ & $6 \quad(22.2)$ & $19(70.4)$ & 11.34 \\
\hline only bortezomib & $\mathrm{n}=47$ & $6 \quad(12.7)$ & $12(25.5)$ & $30(63.8)$ & 8.92 \\
\hline $\begin{array}{l}\text { bortezomib and thalidomide as previous } \\
\text { therapy }\end{array}$ & $n=51$ & $3 \quad(5.9)$ & $9 \quad(17.6)$ & $27 \quad(55.1)$ & 5.57 \\
\hline
\end{tabular}

Abbreviations: RI, renal insufficiency; CR, complete remission, VGPR, very good partial remission, ORR overall response rate, $\mathrm{PR}$, partial response, TTP time to progression

Tab. 2b: Prognostic value of various parameters on Overall Survival

\begin{tabular}{|c|c|c|c|c|}
\hline & Hazard ratio & .95 lower $\mathrm{CI}$ & .95 upper CI & p-value \\
\hline RI yes vs. No & 1.4 & 0.82 & 2.24 & 0.233 \\
\hline Moderate RI vs. No & 1.2 & 0.63 & 2.11 & 0.637 \\
\hline Severe RI vs. No & 1.7 & 0.90 & 3.05 & 0.107 \\
\hline bortezomib or thalidomide & 3.2 & 1.22 & 8.37 & 0.018 \\
\hline Only thalidomide & 2.5 & 0.83 & 7.76 & 0.103 \\
\hline Only bortezomib & 3.7 & 1.35 & 9.91 & 0.011 \\
\hline bortezomib and thalidomide as previous therapy & 6.4 & 2.50 & 16.55 & ¡0.001 \\
\hline
\end{tabular}

Abbreviations: $\mathrm{RI}$, renal insufficiency; $\mathrm{Cl}$, confidence interval 
Tab. 3a CTC grade $3 / 4$ toxicity according to renal function

\begin{tabular}{|c|c|c|c|c|c|c|c|c|c|}
\hline Event & $\begin{array}{c}\text { All } \\
n=108\end{array}$ & & $\begin{array}{l}\text { No RI } \\
\mathrm{n}=59\end{array}$ & & $\begin{array}{c}\text { Mild RI } \\
n=31\end{array}$ & & $\begin{array}{c}\geq \text { Moderate RI } \\
n=18\end{array}$ & & $\begin{array}{c}\text { Fisher's exact } \\
\text { Test } \\
\text { (grade } 3 / 4 \text { combined) }\end{array}$ \\
\hline & Grade 3 & Grade 4 & Grade 3 & Grade 4 & Grade 3 & Grade 4 & Grade 3 & Grade 4 & $\begin{array}{l}\text { Normal vs. mild/ } \\
\text { moderate/ severe } \\
\text { RI combined }\end{array}$ \\
\hline $\begin{array}{l}\text { Hematologic } \\
\text { disorder } \\
\text { Neutropenia } \\
\text { Thrombopenia } \\
\text { Anemia }\end{array}$ & $\begin{array}{l}29(26.7) \\
11(10.2) \\
16(14.8)\end{array}$ & $\begin{array}{l}2(1.9) \\
5(4.6) \\
1(0.9)\end{array}$ & $\begin{array}{ll}11 & (18.6) \\
7 & (11.9) \\
6 & (10.2)\end{array}$ & $\begin{array}{l}1(1.7) \\
1(1.7) \\
0(0.0)\end{array}$ & $\begin{array}{ll}11 & (35.5) \\
2 & (6.5) \\
5 & (16.1)\end{array}$ & $\begin{array}{l}1(3.2) \\
3(9.7) \\
0(0.0)\end{array}$ & $\begin{array}{l}7(38.9) \\
2(11.1) \\
5(27.8)\end{array}$ & $\begin{array}{l}0(0.0) \\
1(5.6) \\
1(5.6)\end{array}$ & $\begin{array}{l}0.05 \\
0.79 \\
0.11\end{array}$ \\
\hline $\begin{array}{l}\text { Infection } \\
\text { All kinds } \\
\text { Pneumonia } \\
\text { FUO } \\
\text { Other }\end{array}$ & $\begin{array}{ll}31 & (28.7) \\
15 & (13.9) \\
8 & (7.4) \\
8 & (7.4)\end{array}$ & $\begin{array}{l}1(0.9) \\
0(0.0) \\
1(0.9) \\
0(0.0)\end{array}$ & $\begin{array}{ll}11 & (18.6) \\
4 & (6.8) \\
3 & (5.1) \\
4 & (6.8)\end{array}$ & $\begin{array}{l}1(1.7) \\
0(0.0) \\
1(1.7) \\
0(0.0)\end{array}$ & $\begin{array}{ll}13 & (41.9) \\
8 & (25.8) \\
3 & (9.7) \\
2 & (6.5)\end{array}$ & $\begin{array}{l}0(0.0) \\
0(0.0) \\
0(0.0) \\
0(0.0)\end{array}$ & $\begin{array}{l}7(38.9) \\
3(16.7) \\
2(11.1) \\
2(11.1)\end{array}$ & $\begin{array}{l}0(0.0) \\
0(0.0) \\
0(0.0) \\
0(0.0)\end{array}$ & $\begin{array}{c}0.03 \\
0.03 \\
0.73 \\
1\end{array}$ \\
\hline $\begin{array}{l}\text { Vascular } \\
\text { disorders } \\
\text { DVT } \\
\text { PE }\end{array}$ & $\begin{array}{l}5(4.6) \\
0(0.0)\end{array}$ & $\begin{array}{l}0(0.0) \\
1(0.9)\end{array}$ & $\begin{array}{l}4(6.8) \\
0(0.0)\end{array}$ & $\begin{array}{l}0(0.0) \\
1(1.7)\end{array}$ & $\begin{array}{ll}1 & (3.2) \\
0 & (0.0) \\
\end{array}$ & $\begin{array}{l}0(0.0) \\
0(0.0)\end{array}$ & $\begin{array}{l}0(0.0) \\
0(0.0)\end{array}$ & $\begin{array}{l}0(0.0) \\
0(0.0)\end{array}$ & $\begin{array}{c}0.37 \\
1 \\
\end{array}$ \\
\hline
\end{tabular}

Abbreviations: FUO, fever of unknown origin; DVT, deep vein thrombosis; PE, pulmonary embolism, RI, renal insufficiency

Tab. 3b Frequency of dose reduction and interruption according to renal function

\begin{tabular}{|l|c|c|c|}
\hline Dose reduction & $\mathbf{n}=\mathbf{1 6 7}$ & $\mathbf{3 1 / 1 6 7}$ & $\mathbf{1 8 . 6}$ \\
\hline Entire group & $\mathrm{n}=94$ & $11 / 94$ & 11.7 \\
\hline Normal kidney function & $\mathrm{n}=40$ & $12 / 40$ & 30.0 \\
\hline Mild RI & $\mathrm{n}=33$ & $8 / 33$ & 24.2 \\
\hline Moderate + severe RI & & & \\
\hline Dose interruption & $\mathbf{n}=\mathbf{1 6 7}$ & $\mathbf{2 7 / 1 6 7}$ & $\mathbf{1 6 . 2}$ \\
\hline Entire group & $\mathrm{n}=94$ & $14 / 94$ & 14.9 \\
\hline Normal kidney function & $\mathrm{n}=40$ & $5 / 40$ & 24.2 \\
\hline Mild RI & $\mathrm{n}=33$ & $8 / 33$ & 2.5 \\
\hline Moderate + severe RI & & \\
\hline
\end{tabular}

Abbreviations: RI, renal insufficiency 
Tab. 4 Shift in renal function during treatment with lenalidomide/dexamethasone

\begin{tabular}{|c|c|c|c|c|c|c|c|}
\hline & & $\begin{array}{c}\text { Improvement of } \\
\text { RI (\%) }\end{array}$ & $\begin{array}{c}\text { Response } \\
\text { rate } \geq P R \\
(\%)\end{array}$ & $\begin{array}{c}\text { Unchanged } \\
\text { RI (\%) }\end{array}$ & $\begin{array}{l}\text { Respons } \\
\text { e rate } \\
\geq P R(\%)\end{array}$ & $\begin{array}{l}\text { Worsening } \\
\text { RI (\%) }\end{array}$ & $\begin{array}{c}\text { Response } \\
\text { rate } \geq P R \\
(\%)\end{array}$ \\
\hline Entire group & $\begin{array}{l}n= \\
152\end{array}$ & 17/152 (11.2) & $\begin{array}{l}10 / 17 \\
(58.8)\end{array}$ & $\begin{array}{c}123 / 152 \\
(80.9)\end{array}$ & $\begin{array}{c}85 / 118 \\
(72.0)\end{array}$ & $12 / 152$ (7.9) & $6 / 11(54.5)$ \\
\hline Mild RI & $\mathrm{n}=36$ & $9 / 36(25.0)$ & $5 / 9(55.6)$ & $21 / 36(58,3)$ & $\begin{array}{l}16 / 20 \\
(75.0)\end{array}$ & $6 / 36(16,7)$ & $2 / 6(33.3)$ \\
\hline $\begin{array}{l}\text { Moderate } \quad+ \\
\text { severe RI }\end{array}$ & $\mathrm{n}=28$ & $8 / 28(28.6)$ & $5 / 8(62.5)$ & $18 / 28(64.3)$ & $\begin{array}{l}11 / 17 \\
(64.7)\end{array}$ & $2 / 28(7.1)$ & $0 / 2(0.0)$ \\
\hline
\end{tabular}

Abbreviations: RI, renal insufficiency; PR, partial response 